\title{
Cuentos tradicionales portugueses en el cine: la aportación de João César Monteiro
}

\author{
Recibido: 25/5/2016
}

Aceptado: 9/11/2016

\section{RESUMEN:}

Tras la Revolución de los Claveles, el cine portugués se centró en la búsqueda de las raíces del imaginario nacional. En este contexto, el director João César Monteiro llevó a cabo la adaptación cinematográfica de una serie de cuentos tradicionales lusos entre los que figuran "Blancaflor", "Os dois irmãos e a mulher morta", "Os dois soldados", "As tres cidras do amor", "A mão do finado" $y$ "A donzela que vai à guerra". En ellos recrea y establece toda una red de leyendas, personajes, tradiciones y símbolos de la mitología popular y del patrimonio intangible de Portugal.

PALABRAS CLAVE: Cuentos populares portugueses. Didáctica. Lectura. Cine. Monteiro.

Portuguese folk tales in cinema: João César Monteiro's contribution

\section{ABSTRACT:}

After Revolucão dos Cravos, Portuguese cinema focused on the search for the roots of the national imaginary. In this context, filmmaker João César Monteiro carried out the film adaptation of several Portuguese folk tales which include "Blancaflor", "Os dois irmãos e a mulher morta", "Os dois soldados", "As tres cidras do amor", "A mão do finado" and "A donzela que vai à guerra". They recreate and establish a network of legends, characters, traditions and symbols from popular mythology and intangible heritage of Portugal.

KEY WORDS: Portuguese folk tales. Teaching. Reading. Cinema. Monteiro. 


\section{Introducción}

Desde la perspectiva del Séptimo Arte portugués, la etapa comprendida entre la Revolución de los Claveles ( 25 de abril de 1974) y el inicio de la década de los ochenta se caracterizó por el gusto hacia un cine militante, con filmes de carácter revolucionario e incluso panfletario, y títulos que reflejan el momento histórico en el que fueron rodados. Ahora bien, el denominado "Cine de Abril" no sólo se restringe a lo meramente político, sino que refleja también una obsesión por recoger el habla portuguesa -en lo referente a los distintos dialectos regionales-, por promover movimientos de alfabetización fílmica, por descubrir la riqueza del mundo rural y de la cultura lusa. Sobresale en este sentido Trás-os-Montes (1976), de António Reis y Margarida Cordeiro, película que busca las raíces del imaginario nacional y prosigue, pues, esa corriente de antropología visual inaugurada en 1963 con el largometraje O Acto da Primavera, de Manoel de Oliveira, a propósito de la celebración popular de la Pasión de Cristo en la aldea trasmontana de Curalha.

En este contexto, el también cineasta João César Monteiro decidió explorar los cuentos tradicionales y la etnografía de Portugal a través de una red de leyendas, mitos y símbolos orientada a desvelar la esencia del pueblo luso, adaptándolos a su percepción cinematográfica e inscribiéndolos en diferentes formas de la Historia del Cine.

Las presentes páginas tienen como objetivo la descripción y el análisis de los cinco ejercicios fílmicos (dos largometrajes y tres cortos) en los que Monteiro aborda de forma plástica y visual una serie de cuentos populares portugueses. Partiremos, no obstante, de un sumario retrato de este realizador, tan reconocido cuanto desconocido -esto último, al menos en España-, así como de la intensa relación Literatura/Cine que recorre y define toda su filmografía. 


\section{Breve aproximación a la figura y la obra de João César Mon- teiro}

El legado fílmico de João César Monteiro dos Santos (19392003) es, probablemente, junto al de Manoel de Oliveira, uno de los más reconocidos y prestigiosos dentro del panorama cinematográfico portugués de las últimas décadas.

Autor de una filmografía no demasiado extensa, pero sólida y singular, el director luso ha sabido configurar un universo cinematográfico absolutamente genuino en el que la fusión de lirismo y sátira -así como una voluntad provocadora, transgresora- constituyen su principal sello de identidad. Su cine y su personalidad, polémicos ambos, han suscitado tanta idolatría como animadversión, jamás indiferencia.

La biografía de Monteiro revela dos circunstancias complementarias: una formación autodidacta y una vasta cultura. Este autodidactismo es fruto de una determinada coyuntura familiar, la cual le impidió acceder a unos estudios universitarios que probablemente hubiera despreciado. Sus inquietudes personales, la cercanía con los círculos literarios de los años sesenta y la red de relaciones de trabajo y amistad que estableció a lo largo de su vida con figuras de primer nivel cinematográfico, tanto críticos (principalmente Serge Daney y João Bénard da Costa) como directores (Paulo Rocha, el matrimonio Straub, Otar Iosseliani, etcétera), desembocaron en la prodigiosa riqueza cultural que rezuman sus filmes, sus textos, sus palabras.

El deslumbramiento por el cine es algo que experimenta ya en su infancia, y tanta es su inclinación hacia esta arte que decide convertirla en su modo de subsistencia: así, asumiendo en cierta medida el modelo cahierista, se inicia como crítico (con un notable interés por una meca cultural y cinematográfica como es París y una temprana entrevista a François Truffaut) y evoluciona a director de cine. Su eclosión como realizador se produce, ciertamente, en el último cuarto de su vida -en torno a los cincuenta años-, momento a partir del cual rueda la mayor 
parte de sus películas, con intervalos de tiempo cada vez más cortos y mayor reconocimiento, aunque nunca exento de polémica, hacia su personal y libre poética cinematográfica. Entre sus méritos como cineasta despunta de forma especial el de ser el creador de la denominada "Tetralogía de Dios", un conjunto de cuatro películas protagonizadas por "João de Deus", uno de sus alter ego.

En fin, cualquier recorrido biográfico de João César Monteiro, por somero que sea, permite apreciar una especial incidencia de algunas de sus experiencias vitales en temas recurrentes de su filmografía: la figura de la madre, el trastorno psíquico y la omnipresencia del Séptimo Arte, primordialmente, pero también cierta forma de vida bohemia, la obsesión por la mujer y la actitud laica, entre otras.

\section{La relación literatura / cine en la filmografía de Monteiro}

Una de las características más sobresalientes -si no la que más- que define la poética fílmica de João César Monteiro es la fértil interrelación del Cine con las demás Artes que el artista plantea en todas y cada una de sus películas, en las cuales se percibe una constante atención a la Literatura, la Música, la Pintura, la Iconografía de carácter bíblico y mitológico, y, de forma muy especial, al Cine. Su amigo Sidónio de Freitas Branco Paes incide en esta circunstancia cuando afirma que el cine de Monteiro

Envolve toda uma cultura, em permanente irrupção por via de citações (verbais, musicais, visuais). Por isso, o cinema de João César é um paraíso semântico e entrópico: claro como água, vê-se o fundo, mas há sempre toda a casta de reflexos (...) O cinema de João César Monteiro é ubérrimo nesses "abîmes" ou, para usar un termo de gíria, en sketches (ao modo de Godard), liberalmente condimentados com citações (que são também "abismos", literários, icónicos ou musicais). (Nicolau, 2005: 39-42). 
En términos semejantes se expresa Marcos Uzal al señalar, refiriéndose a la presencia del arte en la filmografía del director figueirense, que

Il est omniprésent dans son oeuvre, sous forme de tableaux, de textes, de musiques, sans oublier les chansons populaires. Ces emprunts, ces citations, ces références ne sont pas exposés dans ses films comme des bibelots précieux, ils sont au contraire aussi présents et vivants que la lumière, le vent ou les arbres. (Revault d' Allones, 2004: 261).

El actor Luís Miguel Cintra añade que João César era "Un homme qui $n^{\prime}$ aimait pas seulement le cinéma, mais aussi la peinture, la musique, la littérature -et qui écrivait lui-même fort bien" (Revault d' Allones, 2004: 128-129). La también intérprete Manuela de Freitas insiste en que "Il était très cultivé. Il écoutait beaucoup de musique, il lisait beaucoup de livres" (Revault d' Allones, 2004: 141). Y, ciertamente, la Literatura, la Música, las Artes Plásticas y el Cine salpican toda la producción cinematográfica de Monteiro.

En este orden de cosas, procedemos al estudio de un conjunto de filmes suyos en los que esta interrelación Literatura/Cine se hace especialmente palpable, pues constituyen la transposición a la gran pantalla de relatos populares del acervo luso.

\section{Las películas basadas en cuentos tradicionales portugueses}

Desde 1977 hasta 1981 João César Monteiro se consagra a la adaptación cinematográfica de textos literarios que exploran la tradición oral portuguesa, es decir, las leyendas y personajes de su mitología popular. Monteiro prosigue con ello la devoción antropológica por realidades culturales y sociales arcaicas, prácticamente desconocidas, típicas de las regiones lusas más aisladas $-\mathrm{y}$, por consiguiente, poseedoras de las tradiciones mejor preservadas- que venía experimentando el documental desde los años sesenta (António Campos, António Reis, Margarida Cordeiro) y 
que se remonta en última instancia, como ya hemos señalado, a O Acto da Primavera, de Oliveira. La novedad es que el cineasta figueirense no aborda esta temática desde el género documental, sino desde la ficción ${ }^{1}$. La base literaria de la que parte Monteiro en estos cinco ejercicios fílmicos es la compilación Contos Tradicionales Portugueses, organizada por los poetas Carlos de Oliveira² y José Gomes Ferreira en 1957.

El profesor Fernando Cabral Martins ha descrito esta fase de la filmografía de João César Monteiro con las siguientes palabras, que remarcan la evolución que se produce desde el folclore al surrealismo:

Esta série dos "contos tradicionais" é um conjunto com autonomia, um período caracterizado do seu trabalho: o encontro de um reino de ficção que ultrapassa o modo típico da Vanguarda dos anos 60 mas não ingressa por isso em qualquer corrente popular, realista, drama ou comédia que se integre no sistema de géneros ou busque a normalidade do gosto. Esse reino de ficção é o do fantástico. E nele dois universos se fundem, distantes e íntimos, o folclore genuino e a arte surrealista. (Nicolau, 2005: 293).

Esta etapa de la filmografía monteiriana comprende dos largometrajes y tres cortos, según se expone a continuación.

1 En este sentido, la realizadora portuguesa Noémia Delgado, adscrita también a la corriente de la antropología visual, seguiría los pasos de Monteiro al abordar la tradición cultural lusa desde la ficción, como demuestra la serie de Contos Fantásticos que rodó para la RTP entre 1979 y 1981, compuesta por estos seis mediometrajes: A Princesinha das Rosas (1979); Tiaga; O Visconde, o Defunto (los dos de 1980); O Canto da Sereia; A Noite de Walpurgis, y A Estranha Morte do Professor Antena (todos de 1981).

2 Carlos de Oliveira (1921-1981) es el autor del romance Uma Abelha na Chuva (1953), en el que se inspiró Fernando Lopes para realizar dos décadas después el prestigioso filme homónimo. 


\subsection{Veredas (1977)}

La película narra el viaje $\mathrm{e}^{3}$ de una pareja desde la comarca de Trás-os-Montes hasta el litoral portugués, un recorrido en el que topan con distintos mitos y leyendas del patrimonio intangible de las regiones por las que transitan (relatos concernientes al desencantamiento de princesas moras, a un tesoro escondido, la fábula de un burro, diversas canciones populares, la danza alrededor de una hoguera por parte de las mujeres de la comunidad, etcétera). No obstante, la parte central del metraje viene representada por una adaptación del cuento popular de "Blancaflor" (Branca-Flor, en portugués): una criatura de los olmos y de las aguas informa a un pastor de cómo su rebaño decrece progresivamente tras el hurto de varias de sus ovejas. Al pedir consejo sobre qué debe hacer, se le recomienda que hable con la joven Blancaflor, que acude a bañarse todos los días al río junto a sus dos hermanas. El pastor se entrevista con ella, quien admite que los robos de ovejas están siendo llevados a cabo por su padre, el Diablo, y aconseja al protagonista que, para recuperarlas, comience a trabajar al servicio de éste pero ocultándole que ambos se conocen. Así lo hace el pastor, a quien el Diablo encomienda obtener vino a partir de un racimo de uvas y fabricar una hogaza de pan con un saco de harina. Con la ayuda de Blancaflor, el protagonista supera las dos pruebas. Extrañado, el Diablo le encarga una tercera prueba más complicada, la de encontrar una guitarra que había perdido en el fondo del mar. Una vez más, el pastor sale airoso gracias a la valiosa complicidad de la joven. Como recompensa, el Diablo invita al pastor a que escoja a una de sus tres hijas como esposa, y la elegida es Blancaflor. Pero se trata de una trampa, pues una vez celebrado el matrimonio, el padre intenta asesinarlos a ambos. Blancaflor y su esposo se dan entonces a la huida. La acción principal del filme y el relato de Blancaflor se entremezclan cuando el Diablo se detiene en su persecución para

3 De forma muy oportuna, los títulos de crédito iniciales y finales se desarrollan sobre el lienzo de la pintora portuguesa Maria Inês da Silva Carmona Ribeiro da Fonseca, más conocida como Menez, titulado L'Invitation au Voyage. 
preguntar a la pareja que recorre Trás-os-Montes si han visto pasar a dos jóvenes a caballo. El mito de que el río Duero nace del flujo vaginal de una mujer ${ }^{4}$ pone punto final al filme.

La transposición fílmica que lleva a cabo Monteiro prima el comparatismo iconográfico: así, por poner un único ejemplo, un hórreo puede transformarse en un templo griego, en una especie de arte povera aplicado al cine. La influencia pasoliniana y bergmaniana es evidente, tanto por la capacidad de leer el paisaje y a los protagonistas desplazados desde el cuento hasta la realidad (caso de Pier Paolo Pasolini en el conjunto de su filmografía de fuentes mitológicas y literarias) como por el simbolismo que se confiere a estos y revelan los contraluces, de nítida inspiración en clásicos de Ingmar Bergman como El Séptimo Sello (Det sjunde Inseglet, 1957).

\subsection{A Mãe (1978-1979)}

Este cortometraje se conoce también como El rico y el pobre (O Rico e o Pobre), siendo "Os dois irmãos e a mulher morta" el título del cuento que da origen a su argumento ${ }^{5}$. Ante el robo de una vaca, la madre del afectado inculpa a su otro hijo y hermano de éste, Joaquim. Para demostrarlo, la anciana se introduce en un baúl que es trasladado a la casa de Joaquim para que éste lo custodie. Cuando en el transcurso de una conversación entre Joaquim y su esposa se hace alusión a la vaca robada, la madre sale de su escondite; descubiertos en su crimen, la nuera la golpea con un atizador y la mata. Al día siguiente se presenta el hermano de Joaquim a recoger el baúl, convertido ahora en ataúd. Mientras

4 Este cierre será reutilizado años más tarde por Manoel de Oliveira en su película Inquietud (Inquietude, 1998), en el que el Duero aflora de los dedos de oro de otro personaje femenino.

5 Cabe señalar que el título El rico y el pobre coincide con el del cuento número 87 del volumen II de Kinder und Hausmärchen, es decir, de los Cuentos de la infancia y del hogar (1812-1815) de los Hermanos Grimm. 
éste entierra a su madre, la familia de Joaquim sigue alimentándose a base de la carne de la res. La mujer de Joaquim le dice que el sudario con el que se ha enterrado a su suegra es de gran calidad, y le incita a ir a buscarlo. El marido obedece. Después, el otro hermano descubre que su madre ha sido exhumada. Se la entierra de nuevo, pero la nuera vuelve a persuadir a su marido de que le quite a la fallecida el nuevo sudario. Tras su segunda exhumación, deciden enterrarla en el cementerio: allí Joaquim encuentra un cerdo que dos hombres habían abandonado por unos momentos, y hace el cambio con el cadáver. Al darse cuenta de la burla que han sufrido, dichos hombres montan el cadáver en un caballo y le ponen una espada en la mano. En medio de un bosque, un fraile (interpretado por el propio João César) ${ }^{6}$, al cruzarse con tal estampa, cae del caballo en el que iba montado.

Stéphane Delorme considera que A Mãe de Monteiro constituye "(...) Une relecture décapante de La Mère de Pudovkine (...) Une fable féroce qui ne connaît comme antécédent que le cinéma de Buñuel ou le court métrage d' Oliveira La Chasse (1964)" (Delorme, 2003: 15).

Desde una perspectiva cinematográfica, aparte de la apreciación de Delorme, se descubre en la película la importancia del ruralismo como clave estética de la adaptación del cuento. De acuerdo con dicha clave, se prima la identificación de lo campestre con interiores oscuros y pétreos, en ambientes opacos producidos por el humo que desprenden los fuegos del hogar y los calderos.

\subsection{Os dois Soldados (1979)}

Con el cuento homónimo como base, el cortometraje se inicia con el primer plano de un soldado provisto de una máscara antigás. A continuación se ve a otros dos soldados avanzando a través de los matorrales. Llegan a una especie de fortaleza en ruinas, donde comen. Más tarde, cuando de nuevo es hora de

6 En Veredas ya había aparecido como un monje que trata de esquivar al Diablo al paso de éste por las ruinas de un monasterio. 
comer, uno de los soldados se niega a compartir sus provisiones con el otro a pesar de que su compañero sí había repartido sus víveres con él; le dice que sólo está dispuesto a compartir si deja que le saque los ojos con la navaja, y su compañero acepta. Los dos soldados emprenden caminos diferentes. El que ha quedado ciego se sube a un castaño y allí se queda dormido. En mitad de la noche escucha a un par de hombres comentar que la ceguera que padece el rey de aquel lugar podría curarse con las hojas del castaño, pues tienen la propiedad de devolver la vista a los ciegos: el soldado entonces se frota los ojos con dichas hojas y recupera la visión.

Se celebra un espectáculo de gigantes y cabezudos para festejar que un extranjero -el soldado antes ciego- ha devuelto la vista al soberano de aquellas tierras (en efecto, antes de abandonar el castaño el soldado se había provisto de varias hojas con tal finalidad). Se produce el encuentro entre ambos soldados: el que ahora es rico explica a su antiguo compañero las causas de su fortuna. El otro soldado se encamina hacia el castaño porque también quiere triunfar; cuando intenta subir al árbol llegan dos hombres que se lo impiden y un tercero montado a caballo le lanza un disparo. El corto finaliza con el mismo primer plano del principio.

Monteiro ubica su relato fílmico en el marco del género bélico con una iconografía asociada a la I Guerra Mundial (como se desprende de la presencia del barro, el tipo de casco, las máscaras antigás, etcétera). No se trata de una transposición casual ni arbitraria. Y es que la denominada Gran Guerra ha dejado una importante huella en la cultura portuguesa a pesar de que en el país no hubo combates en sí. Así lo reflejan diversos filmes, como, por citar un clásico, Joâo Ratâo (1940), de Jorge Brum do Canto.

\subsection{O Amor das Três Romãs (1979)}

A pesar de que su título coincide con un cuento popular italiano (" $L$ ' amore delle tres melagrane"), este corto supone la adaptación fílmica del cuento tradicional de Oporto "As tres cidras do 
amor" y desarrolla esta trama: el príncipe Cardeal y su escudero cabalgan de noche a través de un bosque. Una misteriosa mujer sale al encuentro de ambos y ofrece tres granadas al príncipe. El escudero parte las dos primeras, y en ambas ocasiones sucede lo mismo: aparecen dos doncellas que piden agua para no morir, pero fallecen. Cuando Cardeal abre la tercera granada aparece una nueva doncella, que también solicita agua. El príncipe la besa, con lo cual le evita la muerte. La joven explica que ella y sus hermanas, prisioneras de un hechizo, estaban encerradas en los mencionados frutos, y que sólo podían salvarse si éstas eran partidas por alguien que estuviera enamorado.

El príncipe marcha para obtener la venia necesaria para contraer matrimonio con la doncella. Mientras tanto, ésta coincide en el bosque con una mujer negra, la cual, al enterarse de que la joven va a casarse con un príncipe, le clava un punzón y la convierte en paloma con el fin de suplantarla. Cuando el príncipe regresa, logra convencerlo de que es la misma con la que pretendía casarse, sólo que el sol ha oscurecido su piel y cabellos. Pero un día, pasados los esponsales, aparece la paloma en la que se había metamorfoseado la doncella, quien, una vez liberada del alfiler, recobra su forma humana. Denuncia entonces lo sucedido y pide la muerte de la impostora. El cuento tiene un final feliz, con el príncipe y la doncella convertidos en marido y mujer.

La representación teatral constituye la estética del filme de Monteiro, como forma de mostrar el artificio subyacente en el relato y para integrarlo en el marco del conjunto del cine portugués, donde lo teatral constituye un referente ineludible desde diferentes perspectivas: la adaptación de obras dramáticas, el protagonismo de gentes del mundo del espectáculo, la trascendencia que se concede a representaciones populares que trasladan lo folclórico a lo teatral y, finalmente, el desarrollo de los filmes en escenarios. Es en esta última categoría en la que se inscribe esta película de Monteiro, la cual llega a influir, entre otros, en largometrajes como El zapato de raso (Le soulier de satin, 1985), o Mi caso (Meu Caso, 1986), ambos de Manoel de Oliveira. 


\subsection{Silvestre (1981)}

Fusión del relato "A mão do finado" y del romance "A donzela que vai para a guerra", este filme, ambientado en el Portugal medieval, gira en torno a la figura de la doncella guerrera. Don Rodrigo, padre de Silvia y de Susana, marcha a la Corte para solicitar al monarca su asistencia a las bodas de Silvia con el rico pero necio Don Paio. En ausencia del padre, las dos jóvenes desobedecen la orden de éste de no abrir la puerta a nadie y dan cobijo a un peregrino compostelano. Tras haber abusado éste sexualmente de su hermana, Silvia cortará la mano derecha del falso peregrino con una espada. Días más tarde, durante la celebración del banquete nupcial, aparece un desconocido que solicita la mano de Silvia. Don Rodrigo le impone como condición que venza a un dragón, prueba que el misterioso caballero supera. Una vez en el castillo de éste, el señor revela a la protagonista que él es el desconocido a quien cercenó la mano, afrenta por la que ahora se dispone a asesinarla. Silvia huye y regresa a la casa de su padre, donde es informada de que Don Rodrigo ha sido secuestrado. Ante tal noticia, la doncella resuelve transformar su aspecto físico e intercambiar su nombre por el de "Silvestre" con el objetivo de marchar a la guerra e intentar averiguar el paradero de su padre. El desmesurado valor que demuestra en el frente le permite pasar desapercibida hasta que resulta herida y el capitán descubre su ardid. Silvia es trasladada a continuación a la Corte, donde se hace presente un nuevo desconocido que negocia con el rey la liberación de Don Rodrigo a cambio de que la hija de éste acepte convertirse en su esposa, oferta que la joven acepta. Sin embargo, en el transcurso del ágape nupcial, Susana demuestra que el prometido es el mismo caballero a quien Silvia amputó la mano. El maligno personaje desaparece entonces ${ }^{7}$.

Cintra Ferreira opina que la exploración de leyendas del imaginario popular que tiene lugar en Silvestre se encuentra próxima

7 Tanto en Silvestre como en O Amor das Três Romãs se detecta un importante sustrato de La Tempestad de Shakespeare. 
a las películas de Hans Jürgen Syberberg Parsifal (1982), y que el plano final en el que los ojos de Silvia se diluyen poco a poco en el cosmos puede estar evocando el comienzo de Dune (1984), de David Lynch (Cintra Ferreira, 1999: 569-570). Gili, por su parte, deja constancia de que determinadas características técnicas y de interpretación de la película de Monteiro están influidas por el filme Perceval el galo (Perceval le Gallois, 1978), de Eric Rohmer (Gili, 1992: 42-43).

No hay que olvidar, en fin, la parodia medievalizante que Monteiro ofrece sobre películas del cine histórico clásico conocido como "de cartón piedra", como puede ser, por ejemplo, Inés de Castro (Inês de Castro, 1945), de José Leitão de Barros.

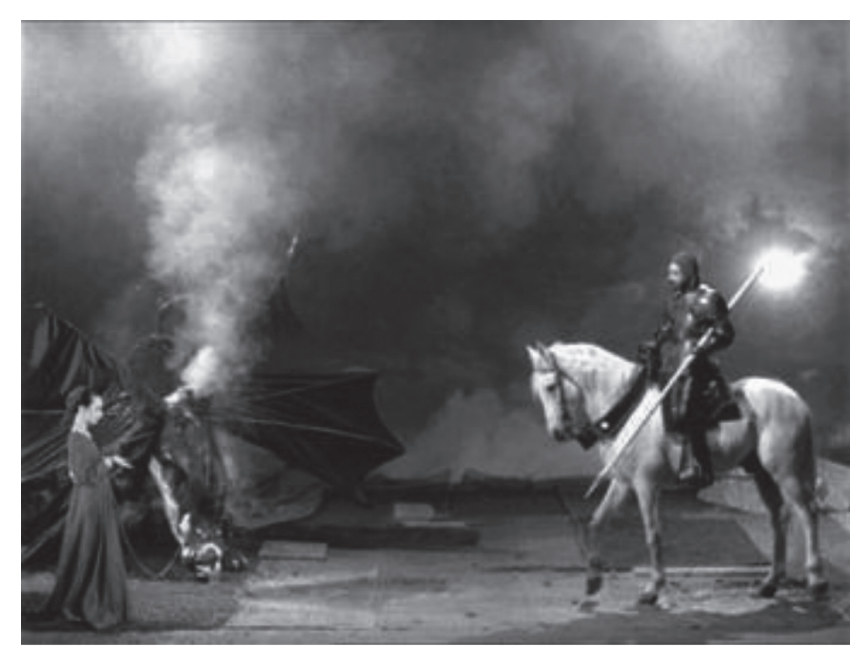

Fotograma del filme en el que se percibe nítidamente el influjo ejercido en la concepción escenográfica de Silvestre por el lienzo San Jorge y el dragón (c. 1455), del pintor renacentista italiano Paolo Uccello.

El peculiar tratamiento que João César Monteiro confiere a la adaptación audiovisual de estos textos incluye también una serie de intertextos fílmicos, según se enumera a continuación: 
a) En lo que se refiere a Veredas, el propio cineasta reconoce que en el episodio del Alentejo hay "uma descarada influência sternbergiana. Estou agora a lembrar-me da Vénus Loura. Peço desculpa, mas não foi consciente" (se refiere a la película La Venus rubia -Blonde Venus, 1932-, de Josef von Sternberg). En otro orden de cosas, Frederico Lourenço evoca el mito de Hilas y las ninfas a propósito de la escena en la que el pastor observa el baño fluvial de Blancaflor y sus hermanas (Lourenço: 1991, 513-514).

b) En otro orden de cosas, Cabral Martins ha apuntado que en los cortometrajes de 1978 A Mãe, Os dois Soldados y O Amor das Três Romãs hay influjo del surrealismo de Buñuel y de la estética pop de la Nouvelle Vague que por aquellos años practicaba Godard.

c) En efecto, el primer plano de un soldado con máscara antigás que abre y cierra Os dois Soldados constituye un intertexto del primer plano de Los carabineros (Les Carabiniers, 1963) en el que el personaje de Miguel Ángel aparece también con una máscara antigás.

d) Finalmente, el título de Silvestre supone en sí una cita del largometraje de George Cukor La gran aventura de Silvia (Sylvia Scarlett, 1935), cuya protagonista se hace pasar por varón e intercambia su nombre, Sylvia, por el masculino "Sylvestre" ("Sylvester", en inglés). Aquí reside la clave cinematográfica de que, en la película del realizador portugués, el personaje interpretado por Maria de Medeiros se llame "Silvia" y de que, en su proceso de masculinización, sustituya este antropónimo por el de "Silvestre". Laurence Giavarini, en su crítica de esta cinta de Monteiro, establece un paralelismo entre el final de Silvestre (la protagonista aparece de frente con un fondo estrellado) y el desenlace de La Strada (1954), de Federico Fellini, con el personaje de Zampanò en la playa bajo un cielo con numerosas estrellas (Giavarini, 1992: 52-54). 


\section{Algunas reflexiones para concluir}

La adaptación de cuentos al Séptimo Arte constituye prácticamente un género cinematográfico propio, y reviste múltiples variantes, desde las versiones infantiles firmadas por la factoría Disney (Disney-Pixar en los últimos tiempos), que han hecho las delicias de los niños de muchas generaciones, pasando por los cuentos tradicionales japoneses recreados por Kenji Mizoguchi en Los cuentos de la luna pálida (Ugetsu monogatari, 1953) o el arquetipo de Cenicienta a partir del cual se construye Pretty Woman (1990), de Garry Marshall (Balló: 1997, 205), hasta llegar a aportaciones tan recientes como Blancanieves y la leyenda del cazador (Snow White and the Huntsman, 2012), de Rupert Sanders, o Maléfica (Maleficent, 2014), también de Disney pero ajena a la animación.

Las películas de João César Monteiro, abundantes en referencias literarias, constituyen un excelente ejemplo de las relaciones que el Cine establece y mantiene con las demás Artes, de forma que la investigación del corpus fílmico de este realizador portugués puede ser enfocada desde los parámetros de la intertextualidad y la Literatura Comparada. Así sucede con las cintas que rodó entre 1977 y 1981, lapso en el que se dedicó exclusivamente a la adaptación cinematográfica de cuentos tradicionales lusos siguiendo la tendencia antropológica imperante en el cine portugués tras la Revolução dos Cravos.

A lo largo de las páginas precedentes se han contextualizado, descrito y analizado los cinco filmes en los que Monteiro rescata para la gran pantalla los relatos populares "Blancaflor", "Os dois irmãos e a mulher morta", "Os dois soldados", "As tres cidras do amor", "A mão do finado" y "A donzela que vai à guerra". Recrea en ellos una serie de leyendas, mitos, tradiciones y personajes populares con los que contribuye a desenterrar, restaurar y conservar el patrimonio inmaterial e intangible de Portugal, en una reivindicación cultural en la que priman el enfoque cinematográfico y, también, metafílmico. Y lo hace desde su estética particu- 
lar, subrayada por el hecho de que se trata de películas de muy bajo presupuesto. Cabe destacar, asimismo, cómo el cineasta consigue imprimirles una iconografía particular al entremezclar en la adaptación de los cuentos elementos propios de la Historia del Cine, como son los citados intertextos de Sternberg, Buñuel, Godard y Cukor. En la acuñación de tal iconografía desempeña también un papel importante el recurso al arte pictórico, como bien demuestra el tableau vivant conseguido a partir del lienzo de Uccello San Jorge y el dragón.

En fin, los filmes de João César Monteiro sobre la mitología popular lusa suponen un material propicio para reflexionar sobre la interrelación de las distintas artes, como se desprende del vínculo Literatura/Cine y Cine/Iconografía del que se ha dejado constancia en las presentes páginas.

\section{Referencias bibliográficas}

Balló, Jordi y Pérez, Xavier (1997). La semilla inmortal. Los argumentos universales en el cine. Barcelona: Anagrama.

Cintra Ferreira, M. (1999). Silvestre (1981). Um filme de João César Monteiro. Textos Cinemateca Portuguesa, 60, 569-570.

Delorme, S. (2003). La Mère, sublime déchet. Cahiers du Ciné$m a, 585,15$.

Giavarini, L. (1992). Une histoire de l'homme. Cahiers du Cinéma, 460, 52-54.

Gili, J. A. (1992). Sylvestre. La main du diable. Positif, 381, 42 43.

Grimm, J. y W. (2015). Cuentos completos I. Madrid: Alianza Editorial.

Lourenço, F. (1991). Veredas. Textos Cinemateca Portuguesa, 44, 513-514. 
Nicolau, J. (2005). João César Monteiro. Lisboa: Cinemateca Portuguesa-Museu do Cinema.

Oliveira, C. y Gómes Ferreira, J. (1985). Contros tradicionais portugueses. Lisboa: Iniciativas Editoriais.

Revault D'Allonnes, F. (2004). Pour João César Monteiro «Contre tous les feux, le feu, mon feu». Paris: Yellow Now.

Angélica García-Manso UNIVERSIDAD DE EXTREMADURA 
